\title{
Chinese SMEs' Sourcing Practices and Their Impact on Western Suppliers
}

\author{
Matthias Wandfluh, Christian Schneider, and Paul Schönsleben \\ ETH Zurich, BWI Center for Industrial Management, Zurich, Switzerland \\ \{mwandfluh, cschneider, pschoensleben\}@ethz.ch
}

\begin{abstract}
Whereas many countries are still suffering from the aftermath of the financial crisis, China's continuous economic growth offers an opportunity for Western companies to reach their growth targets. More and more, Western companies are starting to see Chinese companies not only as sourcing partners but also as potential customers (B2B). While internationally operating Chinese companies are used to purchasing goods from Western companies, for Chinese SMEs this process constitutes a huge challenge. By addressing buyer-supplier relationships from the point of view of Chinese SMEs as buyers, this paper approaches an often neglected topic. Based on an interview series conducted with representatives from Chinese companies, this paper discusses the sourcing behavior of Chinese SMEs and the change of supply base over time. The paper offers valuable insights for Western suppliers and Chinese buyers on how to build and improve their relationship and on how to strengthen their competitive position.
\end{abstract}

Keywords: Supply Chain Management, China, SME, Change of Supply Base.

\section{Introduction}

The Chinese market is gaining enormous attention from internationally operating Western companies. Increasing cost pressure due to growing global competition encouraged Western companies to push sourcing components in low wage countries like China. However, industrial Western companies are starting to see Chinese companies not only as sourcing partners but also as potential customers (B2B). The evolving market potential in China is an opportunity for Western companies to compensate the often unsatisfactory growth of Western markets.

While most studies focus on raising export figures of China (see e.g. [1]), also import figures increased during the last years. Looking at specific commodities, the enormous potential of the Chinese market emerges (see figure 1). For mechanical and electrical products for example, the export volume increased by 15.8 percent annually between 2006 and 2011 whereas the import volume reached an annual increase of 12.9 percent. In the commodity of high and new technology products, the annual growth of import volume was 14.2 percent and thus even exceeded the annual growth of the export volume (14.0 percent). 


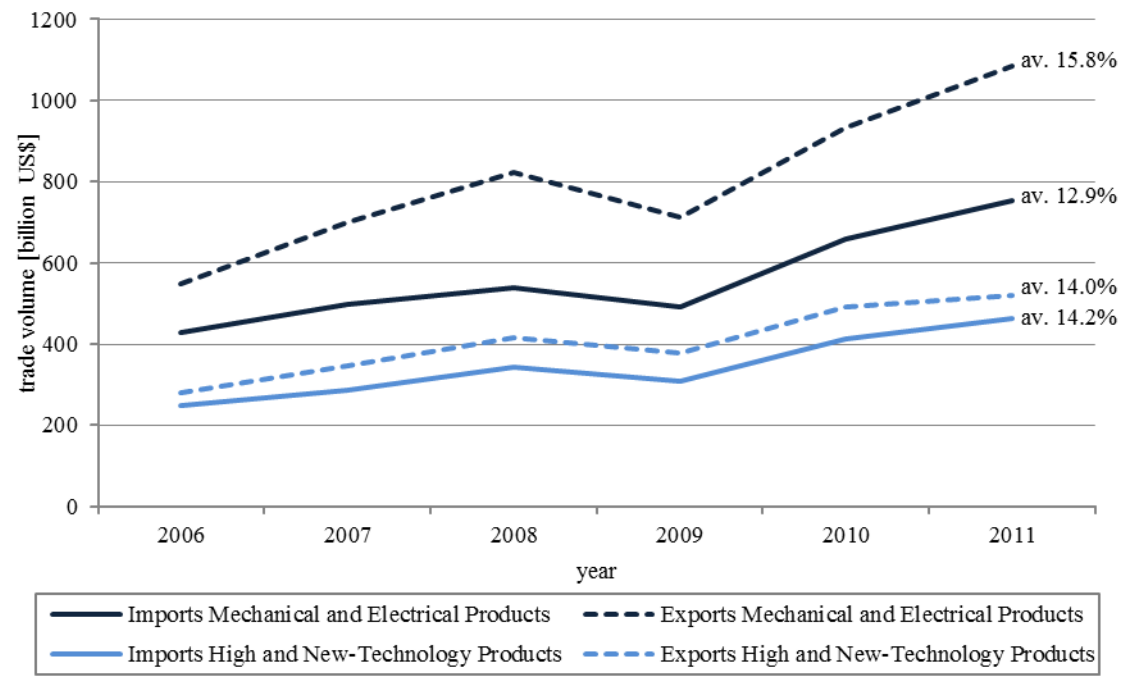

Fig. 1. Import figures of Chinese companies by commodity ${ }^{1}$

As these figures show, Chinese companies do not only export goods to Western countries, more and more especially in the area of high-tech products they also purchase goods from Western suppliers. This trend is not only caused by large international companies in China, also Chinese SMEs, representing more than $99 \%$ of the Chinese companies [2], are increasing their import activities. Although official figures are sketchy and the definition of a SME in China is quite complex and depend on the industrial sector [3], Liu argues that up to 70 percent of all import and export activities are performed by SMEs [4]. Due to various problems as difficulties to access credits or limited technological and managerial capabilities [3], in comparison with larger companies they have other needs which in literature so far are often neglected. Apart from the fact that most studies mainly focus on large international companies, many studies have just analyzed the supply chains characterized by Western buyers and Asian suppliers (see e.g. [5-7]) or discussed entry strategies for Western companies going to China (see e.g. $[8,9]$ ). This exploratory study follows another approach and highlights the requirements and procedures of buyers of Chinese SMEs when purchasing from Western suppliers. For that purpose, this paper analyzes the sourcing processes of Chinese SMEs and characterizes the process of supplier substitution from Western to local suppliers.

\section{$2 \quad$ Background and Research Questions}

The sourcing process of a company strongly depends on its organizational setup. While in large, global companies the purchasing department may have different shapes, SMEs mostly have a central purchasing department and the responsibility lies

${ }^{1}$ Data from "BRICS Joint Statistical Publications 2012". 
in the hands of very few persons having limited knowledge, limited capacity and limited access to technology (see e.g. [2, 10, 11]). While previous studies focused on differences between different types of local suppliers [12] or on Chinese subsidiaries of Western companies as buyers [13], there is to our best knowledge no information available on how sourcing processes in Chinese SMEs differ according to the location of their suppliers. Our first research question is therefore the following:

- R1: Do Chinese SMEs apply different sourcing processes when sourcing from local suppliers as compared to Western suppliers?

As important as the sourcing process is the composition of the supply base. The occurring performance improvement of local supplier especially regarding quality might result in a change of the supply base towards more local suppliers. Although this trend is well known in practice, in research there is hardly evidence on what are the drivers for this change. Especially how this trend appears in Chinese SMEs is not known. Therefore, our second research question is the following:

- R2: How does the supply base of Chinese SMEs change over time and what are the drivers for this change?

\section{Methodology}

The results of this paper are based on six exploratory case studies conducted with Chinese companies headquartered in the Shanghai area (see table 1). Ensuring the comparability of the observed cases, they all belong to the industry of mechanical and plant engineering. All companies purchase a wide range of products: from very simple ones to high-tech products. The chosen method of data collection are semistructured interviews. The interviews were carried out in summer 2011 with highranked executives of the respective company (CEOs or chiefs of purchasing/engineering). The case studies consist of two parts. The first part deals with the characteristics of Chinese SMEs as buyer, their specific requirements concerning procurement and their purchasing processes. The second part focuses on the selection of the supply base and the factors inducing change over time.

Table 1. Case study sample

\begin{tabular}{lrrr}
\hline No. & Years operating & Turnover 2010 & Employees (thereof in Sourcing) \\
\hline 1 & 8 & 5 Mio. USD & $22(2)$ \\
2 & 14 & 5 Mio. USD & $40(3)$ \\
3 & 28 & 25 Mio. USD & $50(3)$ \\
4 & 13 & 22 Mio. USD & $260(10)$ \\
5 & 8 & 11 Mio. USD & $80(4)$ \\
6 & 11 & 10 Mio. USD & $40\left(10^{2}\right)$ \\
\hline
\end{tabular}

\footnotetext{
${ }^{2}$ Number of employees in management, including sourcing.
} 


\section{$4 \quad$ Results}

In this section, the results of the case study research regarding the differences in sourcing processes for Western and local suppliers and the change of the supply base over time are presented. Furthermore, the impact for both, Western suppliers and Chinese SMEs as customers, is derived.

\subsection{Chinese SME's Sourcing Processes}

Compared to large, international companies, purchasers of Chinese SMEs have different needs. In addition to the restricted capacity (see table 1), limited know how and insufficient technology access, many interviewees argued that the main differences lie in high flexibility requirements. These constraints and requirements face different characteristics of Western and local suppliers affecting the sourcing processes on strategic as well as on operative level and leading to a separate sourcing process for Western and local suppliers. The most significant differences identified during our research are described in the following.

\section{Strategic Sourcing}

Before supplier negotiations start, the buyer has to identify possible suppliers. For Chinese SMEs it is hard to find new Western suppliers. Problems often mentioned are language barriers, long distances to possible suppliers and difficulties in identifying skills of possible suppliers. When searching for Western suppliers, Chinese SMEs mainly focus on internet searches, visited exhibitions and recommendations of peers. The process is very similar to searching local suppliers. Once a possible supplier is identified, usually a supplier qualification takes place. Whereas Chinese suppliers are audited very properly, Western suppliers often are not visited at all. The most frequent argument for this circumstance is the high (travelling) costs associated with visiting Western supplier for qualification. If at all, Western suppliers are visited in the context of attending an exhibition or another event taking place in the same area. This is also valid for regular supplier audits, while local suppliers are visited regularly in a given period, Western suppliers in general are not audited at all as the buyer has more trust in the good quality. However, if the required quality is not reached, Chinese buyers do not hesitate to change the supplier.

Compared with local suppliers, communication with Western suppliers proves more challenging. While several Western suppliers have local sales offices or even local production facilities, others can only be contacted by a third-party agency or through headquarter. This may cause long communication paths and thus little flexibility. Furthermore, this may result in difficulties because of different languages and cultures. Local offices simplify the communication; flexibility however hardly improves because most of the sales offices are guided by headquarters. The differences in communication are also reflected in the personal relationships to the suppliers, which are often closer and less formal to local suppliers as compared to Western suppliers. However, most of the interviewed companies argue that this strongly depends on the organizational setup of their supplier. For suppliers running a local office with 
local sales persons, the language and cultural barriers dissolve, leading to comparable types of communication and relationships. Especially for complex products needing additional consulting, the interviewed Chinese SMEs often see local support as a necessity in order to select right components and install them professionally. Close collaborations with local suppliers may also manifest in R\&D collaborations. In contrary to most Western suppliers, local suppliers sometimes do not have their own R\&D department. Depending on the complexity of the components and the available know how of the supplier, deeper R\&D collaboration might be essential to enable the supplier to produce the product at the needed quality. On one hand this is seen as an additional burden compared to Western suppliers, however, it ensures the flexibility of local suppliers and the realization of product requirements.

\section{Operative Sourcing}

Looking at the operative level of sourcing, since most goods are delivered by sea freight the transportation lead time for Western suppliers is significantly higher than for local suppliers. More astonishing, the interviewees argued that also the production lead time of local suppliers is lower. The reason for this is seen in the higher flexibility of the local suppliers and the higher relevance of the Chinese SME as customer for these suppliers. Whereas Chinese SMEs usually deal with large international Western companies supplying many companies in various countries, local suppliers in the corresponding fields are in general smaller and thus buyers have more weight. Regarding supplier integration, the degree of integration for Western suppliers is significantly lower. From an ERP software point of view, the analyzed SMEs don't integrate the suppliers at all, also within their own company they use rather simple software tools. However, looking at other types of integration as for example sharing of production plans, forecasts and demand figures or customization of packaging, the local suppliers are better integrated into business processes and regular meetings with local suppliers strengthen this integration.

Differences are also seen in the process of problem solving. The interviewed persons indicated that problem solving with local suppliers is less formal and faster than with Western suppliers. This is only partly due to the fact that the distance between supplier and buyer is much longer. The basic attitude of the interviewees was that Western suppliers spent more time on clarifying the responsibilities than solving the problem. Although this statement is to be treated with caution, it says that local suppliers are in general faster in reacting to problems and tend to accept responsibility easier. However, once the problem is approached, they mentioned Western suppliers come up with more sustainable solutions.

\subsection{Change of Supply Base}

The analysis of the way Chinese SMEs evaluate the supplier performance has shown that, while Western suppliers perform better in the target area quality, local suppliers outperform in the areas delivery, flexibility and costs. If Western suppliers therefore are not able to improve in other target areas, the improving quality performance of local suppliers may result in change of the supply base over time. This trend was 
confirmed by the interviewed Chinese SMEs. The factors influencing the change of supply base are discussed in the following. The study shows while for example at a new product launch the share of Western components comparatively high, it significantly decreases during the following years, Western supplier's components are more and more replaced by local substitutes (see figure 2a). The shape of the supply base curve depends on three impact factors: speed of adaptation $(t 1-t 0)$, initial share of Western Supplier's components $(s 0)$ and minimum share $(s 1)$. In order to sell more components, Western suppliers thus have the possibility to delay the speed of adaptation $\left(t 1^{\prime}-t 0\right)$ or to increase the initial $\left(s 0^{\prime}\right)$ respectively the minimum share $\left(s 1^{\prime}\right)$ (see figures $2 b, 2 c, 2 d$ ).

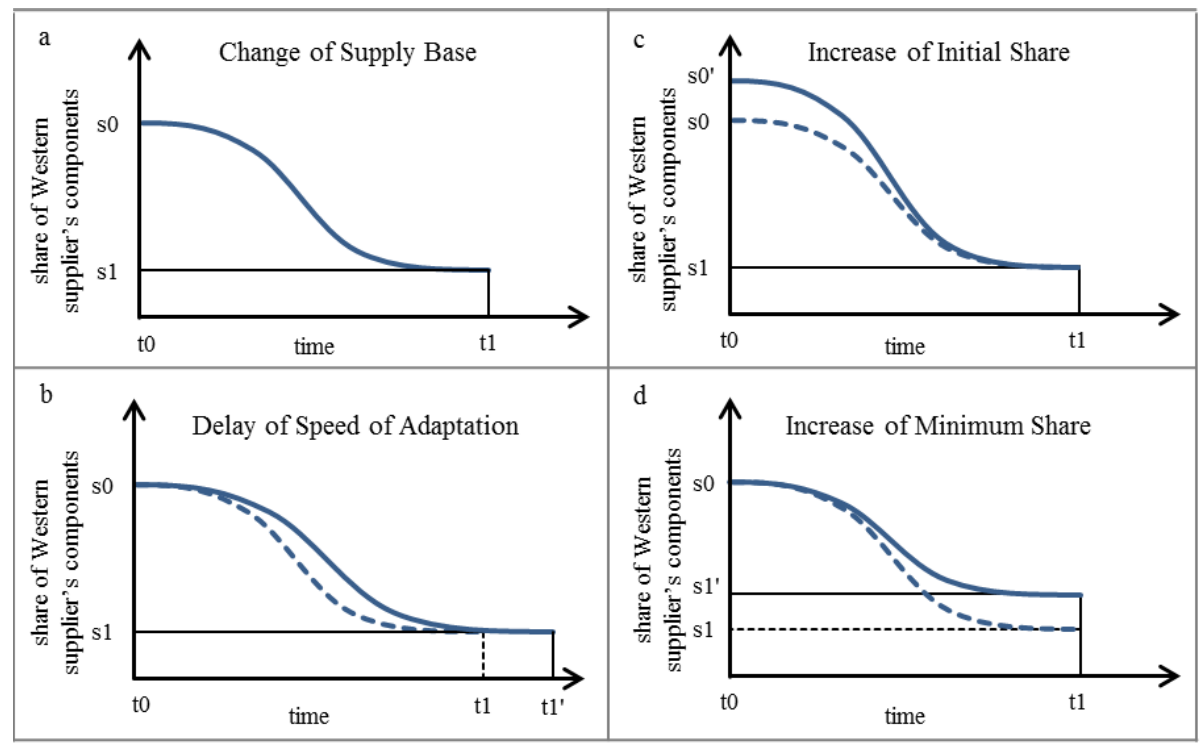

Fig. 2. Adaptions of the change of supply base over time

The speed of adaptation depends on various factors. On one hand, the availability of local substitutes having the corresponding certifications respectively the time needed to deliver the components at similar quality are the main boundaries for a fast adaptation. Having a good relationship and collaboration with the Western supplier may decrease the pressure for a fast change. The initial share provided by Western suppliers strongly depends on product requirements and the availability of local substitutes. However, having already delivered components for previous products, Western suppliers initially are often preferred to local suppliers because of simpler product launches. Particularly for complex components needing additional consulting Western suppliers are favored. Quite often Western suppliers, although they are replaced for the initial product, receive again a delivery contract at new product launches. The availability of local suppliers and the competitiveness of Western suppliers (especially regarding price) compared to local suppliers influence the minimum share of Western supplier's components to a great extent. However, especially for high tech 
products, it is often the end customer defining specific core components and the corresponding manufacturer. While for many components Chinese SMEs can choose freely which supplier to select, the core components are bound to a (Western) supplier. For these core components Chinese SMEs as buyers and their customers are often willing to accept additional purchasing costs.

Western suppliers may pursue different strategies to fit the requirements of Chinese SMEs and to avoid being replaced by local suppliers. The most mentioned factor ensuring long term relationships was the availability of local contact persons speaking the same language. This also simplifies the purchasing processes as described in section 4.1 and facilitates communication to a great extent. In some cases change of supply base may not necessarily lead to reduced quantities delivered by Western suppliers. Although many components of Western suppliers are partly replaced over time, some interviewees argued that the overall growth in sales is higher than the replacement rate. For Western suppliers, this can result in increasing sales rate while the percentage share of components delivered decreases.

\section{Conclusion}

While many previous studies focused on how to source from China, this exploratory study analyzes the needs and the purchasing processes of Chinese SMEs as buyers and the resulting requirements for Western companies. By addressing buyer-supplier relationships from Chinese buyers' point of view, this paper approaches a so far often neglected topic and contributes to research as well as practice. The case studies show that purchasing processes for Western and local suppliers differ strongly. While the collaboration with local suppliers is closer and less formal, long distances as well as language and cultural barriers burden the relationship to Western suppliers. Whenever possible, Chinese SMEs prefer working with local contact persons. Especially when they purchase high tech components from Western suppliers, there might be a great need for additional consulting and support in selection and installation of components and product development.

Due to increasing cost pressure, Chinese SMEs are forced to decrease the purchasing costs. Particularly if Western suppliers are not competitive regarding price and if local substitutes are available, it is only a matter of time until the Western suppliers are replaced. In this study we characterized this trend and identified various factors influencing adaptation time, initial and minimal share of components provided by Western suppliers. Frequently mentioned factors were availability of local suppliers, product or customer requirements, consulting by supplier and relationship to suppliers. While some of these factors cannot be affected by the suppliers, others strongly depend on the supplier's adaptability.

The findings offer valuable insights for Western companies trying to attract Chinese customers and competing against Chinese suppliers. Focusing on Chinese SMEs, the paper discusses an increasingly important topic. The practical implications can be used by both parties as a reference on how to build and improve their relationship and on how to strengthen their competitive position. The findings should be used as a basis for further, more generalizable research extending the results to other (Asian) countries and to other industries. 


\section{References}

1. Wang, J., Ngoasong, M.Z.: The internationalization process of Chinese SMEs: does globalizing wholesale markets play a role? Strategic Change 21, 143-157 (2012)

2. Singh, R.K., Garg, S.K., Deshmukh, S.: The competitiveness of SMEs in a globalized economy: Observations from China and India. Management Research Review 33, 54-65 (2009)

3. Cunningham, L.X.: SMEs as motor of growth: A review of China's SMEs development in thirty years (1978-2008). Human Systems Management 30, 39-54 (2011)

4. Liu, Y.: Chinese SMEs: Successful Factors, Constraints and Future Prospects. The Keizai Ronkyu 142, 47-60 (2012)

5. Ruamsook, K., Russell, D.M., Thomchick, E.A.: Sourcing from low-cost countries: Identifying sourcing issues and prioritizing impacts on logistics performance. The International Journal of Logistics Management 20, 79-96 (2009)

6. Hall, C.: When the dragon awakes: Internationalisation of SMEs in China and implications for Europe. CESifo Forum 8, 29-34 (2007)

7. Carter, J.R., Maltz, A., Yan, T., Maltz, E.: How procurement managers view low cost countries and geographies: a perceptual mapping approach. International Journal of Physical Distribution \& Logistics Management 38, 224-243 (2008)

8. Meyer, K.E., Estrin, S., Bhaumik, S.K., Peng, M.W.: Institutions, resources, and entry strategies in emerging economies. Strategic Management Journal 30, 61-80 (2009)

9. Johnson, J., Tellis, G.J.: Drivers of success for market entry into China and India. Journal of Marketing 72, 1-13 (2008)

10. Gunasekaran, A., Marri, H., McGaughey, R., Grieve, R.: Implications of organization and human behaviour on the implementation of CIM in SMEs: an empirical analysis. International Journal of Computer Integrated Manufacturing 14, 175-185 (2001)

11. Vos, J.P.: Developing strategic self-descriptions of SMEs. Technovation 25, 989-999 (2005)

12. Millington, A., Eberhardt, M., Wilkinson, B.: Supplier performance and selection in China. International Journal of Operations \& Production Management 26, 185-201 (2006)

13. Schneider, C., Finke, G., Sproedt, A., Alard, R., Schönsleben, P.: Enabling Manufacturing Competitiveness and Economic Sustainability. In: Proceedings of the 4th International Conference on Changeable, Agile, Reconfigurable and Virtual production (CARV 2011), pp. 384-390 (2012) 